\title{
LA DEIXIS Y LA ANÁFORA COMO HERRAMIENTAS DEL DISCURSO JUDICIAL EN LA NUEVA ESPAÑA EN EL SIGLO XVI ${ }^{*}$

\author{
THE DEIXIS AND THE ANAPHORA AS TOOLS \\ OF JUDICIAL DISCOURSE IN NEW SPAIN IN THE \\ SIXTEENTH CENTURY
}

\author{
Idanely Mora Peralta \\ Universidad Nacional Autónoma de México \\ idanelym@gmail.com
}

\begin{abstract}
Resumen
Este trabajo es una contribución al estudio de las estructuras indiciales en la documentación colonial. Me propongo analizar cuáles fueron las formas deícticas y anafóricas más recurrentes que emplearon los secretarios de la Santa Inquisición para elaborar el discurso jurídico de los años treinta en el siglo XVI, a partir del examen directo de cuatro expedientes que rescaté del Archivo General de la Nación, México. El estudio me permitirá demostrar, por un lado, cuáles son los motivos que mueven al redactor para que haga uso de estos recursos a la hora de establecer referencias situacionales o contextuales, por el otro, confirmar que estas estructuras son pieza clave para actualizar la información contenida en el texto jurídico, así como para evitar la ambigüedad.
\end{abstract}

Palabras Clave: deixis, anáfora, demostrativos, adverbios

\section{Abstract}

This work is a contribution to the study of the indicial structures in the colonial documentation. I propose to analyze which were the most recurrent deictic and anaphoric forms used by the secretaries of the Holy Inquisition to elaborate the legal discourse in the sixteenth century, from the direct examination of four files that I rescued from the General Archive of the Nation, Mexico. The study will allow me to demonstrate, on the one hand, what are the reasons that motivate the editor to make use of these resources when establishing situational or contextual references, on the other, to confirm that these structures are a key element to update the information contained in the legal text, as well as avoiding ambiguity.

KEYwORDs: deixis, anaphora, demonstrative, adverbs

\footnotetext{
"Agradezco las observaciones que realizaron los dictaminadores, así como los comentarios y la bibliografía que me proporcionó la doctora Beatriz Arias Álvarez para la mejora de este trabajo; los posibles errores son responsabilidad mía.
} 
FECHA DE RECEPCIÓN: 09/03/2018

FECHA DE ACEPTACIÓN: 09/04/2018

\section{Introducción}

El participio de decir, dicho, y sus combinaciones, 'la dicha, este dicho, susodicho de arriba', así como el uso de demostrativos y de adverbios son algunos de los recursos que utilizaron escribanos, notarios y secretarios para dar cohesión al texto judicial en la Nueva España durante la época colonial. Hay que advertir que, aunque contamos con algunos trabajos sobre el uso de este participio en textos antiguos como los de Barra (2008) para la península ibérica, Garatea (2010) para el Perú, y Arias (2013) para el español novohispano, no hay estudios pertenecientes a la Nueva España que dediquen un espacio único para las construcciones de este tipo y otros anafóricos y deícticos en procesos inquisitoriales. Ante este panorama, me di a la tarea de analizar la función mostrativa y anafórica que realizan las estructuras conformadas con dicho como: a) artículos la dicha; b) demostrativos este dicho c) adverbio susodicho. Además de las funciones que desempeñan las formas demostrativas como este, aquel; pronombres personales de tercera persona singular o plural: ellos; el relativo: cual; y los adverbios de lugar con función deíctica: allí, aquí, acá y allá. Todo ello con el fin de analizar los recursos y formas utilizados por los secretarios dentro del discurso jurídico de un proceso inquisitorial.

Para este trabajo voy a estudiar los siguientes procesos jurídicos que llevó a cabo la inquisición monástica ${ }^{1}$ en la Ciudad de

\footnotetext{
${ }^{1}$ El papel de los religiosos en la Nueva España fue sustancial, ya que además de cumplir con la labor de evangelización, desempeñaron el cargo de inquisidores como lo fue fray Juan de Zumárraga, primer obispo de México, de la orden de los franciscanos, y segundo en la Nueva España, antes de él estuvo Julián Garcés, un fraile dominico. Los religiosos fueron los encargados de llevar a cabo los procesos contra los indígenas que cometían algún delito que atentara contra los dogmas de la fe católica.
} 
México. El primero es contra Martín Ucelo (Ocelotl) en 1536, indio vecino de Texcoco. El segundo es el proceso del Santo Oficio de la Inquisición contra Mixcoatl y Papalotl en 1537. El tercero contra los indios de Azcapotzalco en 1538. Finalmente, contra don Carlos, indio principal de Texcoco, en 1539. Los escribientes de cada proceso son el secretario Martín de Campos (para el primero), el secretario brigadier Miguel de Barreda (para el segundo), y para el tercero y cuarto, Miguel López de Legazpi. En los tres primeros juicios el intérprete es Alonso Mateos, en el cuarto intervienen el fraile Antonio de Ciudad Real, fray Alonso de Molina y fray Bernardino. La temática de los procesos gira en torno a los delitos de hechicería e idolatría. Debido a la diferencia entre el número de folios que tiene cada proceso, limité el estudio a dos mil palabras.

Me propongo analizar los recursos deícticos y anafóricos a través de un análisis comparativo de los procesos y describir qué implicaciones tiene el uso de estos recursos en este género textual. Aparte de esta introducción, este trabajo contiene los siguientes apartados: 2. La noción de deixis; 3. Dicho en la historia de la documentación notarial; 4. Análisis de los documentos (dentro de este apartado hago las siguientes subdivisiones: 4.1 Estructuras lingüísticas formadas con Dicho en los procesos inquisitoriales; 4.2 Otros recursos anafóricos (que comprende a su vez los apartados: 4.2.1 Los relativos; 4.2.2 Pronombre personal; 4.2.3 Los demostrativos estel aquel); 4.3. Deixis espacial: los adverbios de lugar allí, allá, aquí, acá y, por último, ofrezco unas conclusiones.

\section{La noción de deixis}

El interés por el tema de las expresiones indiciales goza de una trayectoria antigua que va desde los estoicos hasta los recientes estudios de la lingüística del siglo xxI, así lo han hecho saber Barrenechea (1984) y Vicente Mateu (1994). Además, en este recuento, queda de manifiesto la importancia del trabajo de Karl Bühler (1979) en el que se sientan las bases en torno a los estudios sobre las expresiones indiciales: la deixis. Para Bühler estas 
expresiones se deben estudiar a partir de los dos campos del lenguaje: el mostrativo, que corresponde a la situación y el campo simbólico vinculado al contexto. Asimismo, establece tres maneras de señalar: a) deixis ad oculos, b) anafóricos y c) deixis en phantasma. La deixis, en palabras de Eguren, "es un tipo de vínculo referencial entre ciertas unidades o expresiones lingüísticas y aquello que representan en el mundo o en el universo del discurso, por medio del cual se identifican individuos en relación con las variables básicas de todo acto comunicativo: el hablante, el interlocutor, y el momento o lugar en el que se emite un enunciado" (1999: 932). Asimismo, según Carbonero (1979), tomando en cuenta el campo de experiencia cognoscitiva del hablante, del oyente y del contexto de enunciación, las relaciones que establecen el hablante y el oyente se han concebido con base en tres ámbitos: lugar, tiempo y modo. Bajo esta perspectiva, coinciden los trabajos de Pottier (1962), Cifuentes Honrubia (1989) y Fillmore (1997), por mencionar solo algunos. En cambio, Vicente Mateu considera a la deixis como "la referencia a objetos que no son aún conocidos o no están todavía introducidos en el discurso" (situación extralingüística) y a la anáfora como "la referencia a objetos que han figurado ya previamente en el discurso o son generalmente conocidos" (1994: 21).

Para los fines de mi estudio ha de entenderse la deixis como la relación que el hablante establece entre los objetos mentados y las personas gramaticales, mientras que por anáfora la mención de entidades que han aparecido en el discurso o, más propiamente, su recuperación mediante recursos gramaticales (p. ej., el dicho) de las entidades mencionadas antes.

\section{Dicho en la historia de la documentación notarial}

Para entrar en esta materia partimos de la definición que propone el Diccionario crítico etimológico castellano hispánico con respecto a la forma de suso que, según Corominas, susodicho/ 'arriba dicho' viene del latín sursum 'hacia arriba' y suso de la forma castellana antigua suso 'arriba' y que en textos jurídicos es muy común encontrar, susodicho. 
En la documentación peninsular, Barra (2008: 137) dedica un breve apartado para esta forma con base en la documentación notarial de Navarra, León y Castilla. En su estudio advierte que la forma dicho se comienza a utilizar a principios del siglo XIII, y queda establecida a partir del segundo cuarto del xIv. Me permito señalar a continuación, en un breve resumen, lo que este autor señala. Las negritas son mi interpretación al español actual.

- $\quad$ El participio aparece con prefijos como ante, devant, sobre y de (suso)

1. Aquesta heredat antes dita... (dicha)

- Para el resto del siglo XIII se impone el participio en posición posnominal, raramente sin el prefijo:

2. De parte de meu padre y de mia nana sobreditos (sobredichos)

- Para finales del siglo XIII e inicios del XIV aparece dicho sin prefijo y precedido de artículo, pero sobredicho y devant dicho siguen existiendo.

3. Do dito (dicho) casal / aos ditos (dichos) meus yrmaos (del dicho casal/ a los dichos mis hermanos)

- Ya para el segundo cuarto del siglo xIv, continúa el autor, el dicho domina en la anáfora reiterativa.

4. Et los dichos ffrayres dixeron al dicho alcalle [...] de la dicha cibdad [...] que ayan los dichos monesterios.

Bajo este panorama me di a la tarea de revisar grosso modo estas formas en el corpus CODEA <http://www.corpuscodea. es $>$ durante el periodo que va de los siglos XIII al XVI y realizar una aproximación a los usos antes señalados, la búsqueda me permitió encontrar lo que a continuación presento en el cuadro 1: 


\begin{tabular}{|l|c|}
\hline \multicolumn{1}{|c|}{ Formas } & $\begin{array}{c}\text { Número de } \\
\text { apariciones }\end{array}$ \\
\hline ante dita & 0 \\
\hline devant dita & 1 \\
la devant dita & 3 \\
esta devant dita & 2 \\
de la devant dita & 2 \\
\hline Susodicho (suso dicho) & 563 \\
lo susodicho (lo suso dicho) & 364 \\
los suso dichos & 2 \\
\hline sobre dicho & 36 \\
los sobredichos (los sobre & 460 \\
dichos) & \\
\hline
\end{tabular}

Cuadro 1. Estructuras con dicho

Los registros del CODEA para el uso de dicho con los prefijos: ante, devant, sobre y suso muestran que: a) con las formas ante dita $\mathrm{o}$ antes dicha no hay registros $\mathrm{b}$ ) con devant la documentación localizada, que pertenece al ámbito eclesiástico, comprende el siglo XIII en ejemplos como:

Esta devant dita eredat, e la devant dita viña, esta devant dita eredat. (CODEA-0851 | GITHE, CODEA, 2015 Archivo Histórico Nacional | Clero, Navarra, Fitero, carpeta 1398, nº 10. s.d./03/1237 (España, Navarra)

Por último, para las construcciones con susodicho y sobredicho con y sin artículo antepuesto, con base en los datos vertidos en el cuadro 1, observo que susodicho (563 casos) es la estructura mayoritaria cuyo registro se documenta desde 1275, posteriormente aparecerá a comienzos del siglo Xv (1408) con artículo (366). Lo mismo ocurre con su par sobredicho (36 registros) que se documenta hacia finales del siglo XIII. Mientras que con artículo los sobredichos el uso es mucho mayor (460) y se tiene registro de su uso desde 1228. Asimismo, pude notar que el empleo de estas formas y estructuras se utilizó no sólo en documentación eclesiástica, judicial, cancilleresca, sino también en el ámbito particular, pero siempre con mucha menor frecuencia: cartas de compraventa, declaraciones notaria- 
les, cartas de donación a clérigos, carta de privilegio, cartas de particulares.

Para este lado del océano, en el virreinato del Perú, Garatea señala que dicho "mantiene la ligazón temática en lo referido a los participantes en la acción narrada” (2004: 411). Y que es propio de los textos jurídicos, aunque se pueda registrar en otros tipos textuales (con escasa frecuencia).

De lo anterior, y para el caso de la documentación judicial mexicana, me surgen las siguientes preguntas: ¿se continúa con el canon peninsular?, ¿qué otras formas anafóricas y deícticas contribuyen para la cohesión del discurso jurídico? En este estudio se intentará dar respuesta a estas interrogantes.

\section{Análisis de los documentos}

En las actas que conforman los procesos judiciales se observa, a partir del entorno en el que se da la comunicación entre el emisor y el receptor, una deixis ad oculos y una deixis contextual o fórica. El escribano, a través de ciertas estructuras lingüísticas, como es el caso del uso de demostrativos, de pronombres o del relativo compuesto, nos sitúa en una realidad en la que un elemento ha parecido antes en el discurso ( $1 \mathrm{a}-\mathrm{c})$, o bien que no se ha mencionado antes en el discurso ( $1 \mathrm{~d}$ y e) y que, además, no se corresponde en el espacio y tiempo de los interlocutores. ${ }^{2}$

a. En la gran ciudad de México en diez días del mes de julio del año del señor de mil y quinientos y treinta y siete años en el Santo Oficio de la Inquisición ante el Reverendísimo señor don frai Juan de Zumárraga primero obispo de la dicha ciudad (AGN, 1537).

\footnotetext{
${ }^{2}$ En este trabajo únicamente voy a analizar los adverbios demostrativos locativos que aporten información deíctica. Asimismo, para ahondar en el tema de los demostrativos y adverbios se pueden consultar los trabajos de los siguientes autores: Asenjo (1973), Lapesa (1961), Mendizábal (1996), Sánchez (1990) y Terrado (1990), por mencionar algunos. Con respecto al lenguaje jurídico se puede ahondar con el estudio de Bizcarrondo (1995).
} 
b. Su señoría para más información de lo susodicho, mandó llamar y parecer ante sí a Catalina López, muger de Francisco López vecino de esta ciudad, [...] dijo que: -al tiempo que don Pablo gobernador que fue de México, estaba malo este testigo y la beata de las minas de Santa Isabel y con algunas veces a le ver y curar (AGN, 1536).

c. Hizo parecer ante sí su señoría reverendísima en el santo Oficio a Juan indio natural de Azcapotzalco [...] con lo que a ello respondió es lo siguiente. Y asimismo estando presente por lengua e intérprete Alonso Mateos, el cual asimismo juro (AGN, 1538).

d. Exuchicalmatl, vezino de Xucupa, el dicho Andrés lo copo en el camino y le dixo: dónde vas andara conmigo a Quahuchinanco, y el dicho Xuchicalcatl fuese con él y aquella noche durmieron [en] Cuxuncupa y de allí se fueron a Quahochinanco (AGN, 1537).

e. Tomó un pedazo de oro y diolo a una india suya que se llama Luisa y díxole este testigo toma este pedazo de oro y átalo en tu camisa y guárdalo y no digas nada al dicho Min porque ha de venir aquí. Y que este testigo envió luego a llamar al dicho Min (AGN, 1536).

\subsection{Dicho}

Además, se puede advertir cómo el escribiente emplea un repertorio de recursos lingüísticos, como son las construcciones con el participio pasivo dicho, que son utilizados para focalizar o hacer referencia a una entidad, en el entorno contextual.

Las estructuras con el participio pasivo dicho: el dicho, lo susodicho, son las que presentan mayor uso (2a-d).

a. Preguntado qué es lo que sabe del dicho Min, sabe de lo susodicho e si sabe que el dicho Min sea bautizado: -dijo que lo que sabe es que el dicho Min envió a este (AGN, 1536).

b. y es que el dicho Miscoatl había ido al pueblo que se llama Copilla, de la provincia de Guachiname, donde pidió a los indios del dicho pueblo de Copilla que le diesen papel y copal y ulle (AGN, 1537). 
c. E después de lo susodicho, en este dicho día su señoría hizo parecer en el Santo Oficio a Pedro indio vecino e natural de Escapuzalco (AGN, 1538).

d. el dicho don Carlos fue al dicho pueblo de Chiconabtla a ver a su hermana, que es mujer del cacique del dicho pueblo, et como el dicho don Carlos vido hacer las dichas procesiones (AGN, 1539).

Así pues, para darme una idea general del tipo de construcciones que se forman con el participio dicho, hice una clasificación de todas las estructuras que se construyen con dicho. Lo que encontré está reunido en el siguiente cuadro.

\begin{tabular}{|c|c|c|c|}
\hline $\begin{array}{c}\text { Doc. 1 Fecha } \\
1536\end{array}$ & $\begin{array}{c}\text { Doc. } 2 \text { Fecha } \\
1537\end{array}$ & $\begin{array}{c}\text { Doc. } 3 \text { Fecha } \\
1538\end{array}$ & $\begin{array}{c}\text { Doc.4 Fecha } \\
1539\end{array}$ \\
\hline $\begin{array}{c}\text { Artículo + dicho } \\
\text { el dicho } \\
\text { (35casos) }\end{array}$ & $\begin{array}{c}\text { Artículo + dicho } \\
\text { el dicho } \\
\text { (56 casos })\end{array}$ & $\begin{array}{c}\text { Artículo + dicho } \\
\text { el dicho } \\
\text { (37 casos })\end{array}$ & $\begin{array}{c}\text { Artículo + dicho } \\
\text { el dicho } \\
\text { (64 casos })\end{array}$ \\
\hline $\begin{array}{c}\text { Artículo+ } \\
\text { adverbio + dicho } \\
\text { lo susodicho } \\
\text { (13 casos) }\end{array}$ & $\begin{array}{c}\text { Artículo } \\
\text { +Adverbio } \\
\text { +dicho lo } \\
\text { susodicho } \\
\text { (7casos) }\end{array}$ & $\begin{array}{c}\text { Artículo+ } \\
\text { adverbio+ dicho } \\
\text { lo susodicho } \\
(10 \text { casos })\end{array}$ & $\begin{array}{c}\text { Artículo+ } \\
\text { adverbio dicho lo } \\
\text { susodicho } \\
\text { (14 casos) }\end{array}$ \\
\hline $\begin{array}{c}\text { Demostrativo+ } \\
\text { dicho } \\
\text { este dicho } \\
\text { (12 casos) }\end{array}$ & $\begin{array}{c}\text { Demostrativo }+ \\
\text { dicho } \\
\text { este dicho } \\
(6 \text { casos })\end{array}$ & $\begin{array}{c}\text { Demostrativo }+ \\
\text { dicho } \\
\text { este dicho } \\
\text { (8 casos })\end{array}$ & $\begin{array}{l}\text { Demostrativo+ } \\
\text { dicho } \\
\text { este dicho } \\
\text { (16 casos) }\end{array}$ \\
\hline & $\begin{array}{c}\text { Artículo + } \\
\text { preposición+ adv. } \\
\text { el sobredicho }(8) \\
\text { casos }\end{array}$ & & \\
\hline & $\begin{array}{c}\text { Artículo } \\
\text { +adverbio+ } \\
\text { dicho+ } \\
\text { preposición+ } \\
\text { adverbio } \\
\text { el susodicho de } \\
\text { arriba } \\
\text { (1 caso) }\end{array}$ & & \\
\hline
\end{tabular}

Cuadro 2. Clasificación de las construcciones con dicho 
Con base en estos datos, conviene señalar que el número de casos es exiguo para extraer conclusiones definitivas; no obstante, las coincidencias entre ellos son relevantes. Además, como bien se puede observar en el documento 2, de 1537, en el que se encuentran la mayor variedad de estructuras sintácticas; al parecer porque el tema tratado es la hechicería, es decir, los procesados tenían el oficio de lo que actualmente sería un meteorólogo, ya que tanto Mixcoatl como Papalotl eran los responsables de pronosticar el tiempo. En este sentido la argumentación es más detallada de parte de los testigos y requiere de un mayor uso de recursos que permitan ordenar, organizar e identificar los hechos realizados por cada participante, de ahí que el escribiente, el secretario brigadier Miguel de Barreda, reuniera las estructuras lingüísticas necesarias para anclar la información, identificar el discurso de cada uno de los sujetos, evitar ambigüedades $y$, por ende, cohesionar el discurso.

Así pues, tenemos que las formas que más se utilizan en todos los textos son las construcciones anafóricas con artículo + dicho. El artículo dirige al receptor hacia la expresión que ya fue aludida en el discurso y, por tanto, se establece una relación entre ambos sintagmas de correferencia.

En primer lugar, en el siguiente ejemplo, (3), el sintagma nominal la dicha ciudad remite anafóricamente a la Ciudad de México:

En la gran cidad de México en diez días del mes de julio del año de Señor de mil y quinientos y treinta y siete años en el Santo Oficio de la Inquisición, ante el Reverendísimo señor don fray Juan de Zumárraga primero obispo de la dicha ciudad... (AGN, 1537).

En segundo lugar, en (4), tenemos la estructura artículo neutro + susodicho lo susodicho, a través de una deixis contextual el notario hace referencia a toda la información que realizó el testigo líneas arriba: 
(4)

E después de lo susodicho en este dicho día mes y año susodicho, su señoría para más información de lo susodicho mandó recebir juramento en forma debida de derecho (AGN, 1539).

En tercer lugar, se tiene el empleo del demostrativo + dicho (este dicho). Como se muestra en (5), Andrés es el sujeto del que se está hablando y es conocido por el emisor y receptor, ya que líneas arriba fue presentado. En este discurso se vuelve a introducir por medio del demostrativo este dicho. Al utilizar un demostrativo, el antecedente implica un grado de cercanía dentro del discurso, es la persona o cosa a la que se refiere (él, este). Por consiguiente, con esta construcción lo que se espera es focalizar o enfatizar a la persona de la que se está hablando.

Otra vez desde a poco pasó dicho Andrés por el dicho barrio de Atliztaca y luego les pidió copal y papel para hacer sus sacrificios y encantamientos y luego le dieron. Mandó juntar toda la gente de noche y hizo arder el copal y papel en que hizo un gran fuego, y luego les pedricó y dijoles no tengáis miedo que no se helaron vuestros maizales. Todo se hará bien lo que tenéis sembrado, y así los macevales como hizo sus encantamientos y les pedricó creyeron todos en él. Luego le dieron cuatro cargas de mantas y fuese a otro pueblo este dicho Andrés. En cualquiera parte que va, tiene una costumbre que comulga a la gente y él mesmo comulga (AGN, 1538).

Como puede verse en (6), la forma el sobredicho (artículo + preposición + dicho), los referentes papel, copal y ulle (hule) fueron mencionados en el discurso, así como la persona de Mixcoatl, para este caso el antecedente vuelve a nombrarse con uso enfático.

(6)

del dicho pueblo de Copilla que le diesen papel y copal y ulle, que es aquel de que hacen las pelotas, para hacer ciertas hechicerías 
y cosas demoniaticas, supersticiosas haciéndoles creer que con aquello haría cesar la mucha lluvia y tempestades que destruya los maizales y algodonales, que con la mucha agua se van perdiendo. E porque no hallaron papel dieron el copal y el ulle sobredicho y dijo, este que depone, que aunque el sobredicho Miscoatle hizo las dichas cerimonias no dejo por eso de berlo. E después de esto dijo el que depone que, el sobredicho Miscoatle fue a un pueblo subjeto (AGN, 1537).

La siguiente construcción artículo + adverbio + dicho + preposición + adverbio: lo susodicho de arriba la registré únicamente en el documento de 1537. Con este ejemplo queda claro el interés que tiene el secretario por precisar la información que, al ser redundante, se enfatiza en lo antes mencionado.

(7)

el dicho Tlilancalqui me decía que tenía mucho miedo de decir nada contra el dicho Andrés y que no sabía si había de morir o vivir, por esta causa y por más que le decíamos no quería decir su dicho. Todos los que estábamos allí estábamos espantados de tal cosa, nunca tal cosa vi en los días de mi vida ya por muchas razones y amonestaciones y miedo que le pusimos al dicho Andrés ovo de decir su dicho lo cual es lo susodicho de arriba y cuando decía su dicho... (AGN, 1537).

En el ejemplo siguiente el uso del participio enfatiza, por un lado, la presencia del Padre Francisco Ximénez y, por otro, se presenta como una forma característica del lenguaje jurídico:

Y porque no savia firmar rogó al padre fray Francisco Ximénez lo firmase por él. [...] Este que depone con el mesmo juramento y cargo y ruega también al dicho Padre lo firme por él. Y encargosele el secreto y con el cual, dicho Padre frai Francisco Ximénez guardián de Coatitlán fue el intérprete (AGN, 1537). 


\subsection{Otros recursos anafóricos}

\subsubsection{Relativos}

Como segundo recurso anafórico el pronombre relativo compuesto artículo + cual es la estructura más recurrente en la documentación, como se demuestra con los ejemplos siguientes:

a. Que prendió al dicho Montesuma, que habían de venir españoles con barbas a esta tierra, la cual había de ser de ellos (AGN, 1536).

b. En veinte mantas comunes a dos tomines, las cuales recibí yo Alonso Mateos alguacil del Santo Oficio (AGN, 1537).

c. Y que en casa del dicho Tacatecle hay tres ídolos la una de Uchilobos, y la otra de Culenque y otra que se llama Tlalocatecle, los cuales a cuatro meses que vido este testigo y que Huchillobos tiene los labriegos llenos de sangre (AGN, 1538).

d. Siendo intérpretes el padre fray Antonio de Ciudad Rodrigro, principal de la orden del señor san Francisco en esta Nueva España, y su compañero fray Alonso de Molina y fray Bernardino lector del colegio de Santiago por lengua de los cuales dijo que, él viene a denunciar y a decir lo que sabe de don Carlos principal (AGN, 1539).

A partir de los ejemplos expuestos en (9) puedo explicar que lo que motiva el uso frecuente del relativo compuesto frente al simple (que) es una cuestión de concordancia y por lo mismo la delimitación del antecedente, además del carácter explicativo de la oración.

\subsubsection{Pronombre personal}

Asimismo, el pronombre personal de tercera persona del singular o plural es otro elemento que contribuye a establecer las referencias. A través de este pronombre el emisor remite a personas u objetos, y a lo dicho con anterioridad en el discurso. Hay que resaltar que su uso se emplea en cualquier tipo de discurso, oral, escrito, y no es privativo del lenguaje jurídico: 
a. compró al dicho Min una viga grande de ciprés porque en su tierra no la tiene y le dio por ella [...] cueros de venados y llevando (AGN, 1536).

b. Obo en el tiánguez del dicho pueblo de Quahuchinanco un gran bullicio y este bullicio fue porque había allegado al dicho pueblo Andrés, que es el que llaman por nombre y en nombre de yndio Mixcoatl, y la causa de este bullicio fue que entre ellos lo tenían por dios. Y luego le dieron la dicha gente del tiánguez copal y papel (AGN, 1537).

c. Preguntado si sabe quién tenga ídolos algunos en el pueblo de Escapuzalco y hazen sacrificios a ellos dixo que, el Tacatecle del dicho lugar de Escapuzalco hazia que este testigo ayunase cient e días porque dios les diese buenos maizales y temporales, y por otras cosas que este testigo no sabe (AGN, 1538).

d. y esto digote como de tío a sobrino y no cures de andar en eso ni andar haciendo creer a los indios lo que los frailes dicen que ellos hacen su oficio (AGN, 1539).

\subsubsection{Los demostrativos este/aquel}

En cuanto al demostrativo este, desempeña la función de anafórico con referentes cercanos, como bien se muestra en los ejemplos que se exponen en (11). En los casos de $a$ y $b$ hay un grado de cercanía entre el que escribe y el que habla. Llama la atención el caso de $c$, en el que, aunque hay un referente en el discurso inmediato, este es indeterminado, desconocido por el emisor (se da prioridad a la cercanía discursiva):

a. Y mando llamar y parecer ante sí a Catalina López muger de Francisco López, vecino de esta ciudad [...] que es de hedad este testigo de treinta y cinco años poco más o menos y este testigo dixo y de puso este dicho y deposición por lengua del dicho Pedro de Molina intérprete y naguatlato (AGN, 1536).

b. E después delo susodicho en este dicho día su señoría hizo parecer en el Santo Oficio a Pedro indio, bezino e natural de Escapuzalco, y que al cabo de los cient días que ayunaban este confesante 
e los otros sus compañeros se repartían aquellas tortillas entre los muchachos (AGN, 1539).

c. luego vido venir paz que de alguna parte que había basura una sabandija amanera de cigarra, salvo que no tenía alas, este se llama en su lengua pinauiztly (Pinahuiztli) y luego en pos de esta sabandija salió otra a manera de araña que se llama en su lengua tecuantocatl (AGN, 1537).

El demostrativo aquella(s), como término secundario funciona como determinante de un sustantivo, en la mayoría de los casos que he recogido está en femenino. Asimismo, el demostrativo se utiliza para referirse a algo indefinido: aquellas supersticiones, aquellas ancas, aquellas tortillas, aquellos días. De ahí que siempre se registre en oraciones con verbos en pretérito (perfecto e imperfecto). El referente se encuentra lejos del emisor y del receptor, como se puede observar en los siguientes ejemplos:

a. le dijeron que no entrase porque el dicho Min estaba dentro y que ello mandaba y que aquellas ancas que le echaban que eran medicinas (AGN, 1536).

b. que haciendo que hacía aquellas supersticiones y hechicerías sonaba que el diablo le hablaba y le decía haz esto y lo otro y que lo mesmo que hizo en México lo hizo en Teplatazcuco (AGN, 1537).

c. En el dicho ayuno ofresçiendo de aquel copal a Tezcatepucal. E que si mucho pan de tortillas que truxieron con los cosas de sacrifiçios, dixo que hera pan ofresçido Atezcatepucal [...] y que al cabo de los cient días que ayunaban, este confesante e los otros sus compañeros se repartían aquellas tortillas entre los muchachos como pan bendito (AGN, 1538).

d. Puede haber veinte días poco más o menos que haziendo ciertas procesiones y rogativas e disciplinas en el pueblo de Chicona [...] et como el dicho don Carlos vido hacer las dichas procesiones e que en aquellos días no comían sino pescado (AGN, 1539). 
Con los datos anteriores, elaboré el siguiente cuadro de anafóricos en el que documento el número de usos.

\begin{tabular}{|l|l|l|l|l|l|}
\hline Anafóricos & $\begin{array}{l}\text { Doc. } \\
1536\end{array}$ & $\begin{array}{l}\text { Doc. } \\
1537\end{array}$ & $\begin{array}{l}\text { Doc. } \\
1538\end{array}$ & $\begin{array}{l}\text { Doc. } \\
1539\end{array}$ & Totales \\
\hline $\begin{array}{l}\text { Pronombre } \\
\text { relativo }\end{array}$ & 16 casos & 24 casos & 12 casos & 8 casos & 60 \\
\hline $\begin{array}{l}\text { Pronombre de } \\
\text { tercera persona }\end{array}$ & 12 casos & 6 casos & 6 casos & 10 casos & 34 \\
\hline $\begin{array}{l}\text { Demostrativo } \\
\text { este/ aquel }\end{array}$ & $\begin{array}{l}31 / 10 \\
\text { casos }\end{array}$ & $10 / 6$ casos & $12 / 8$ casos & $8 / 6$ casos & $61 / 30$ \\
\hline
\end{tabular}

Cuadro 3. Anafóricos

Los datos nos indican que el pronombre relativo (cual) tiene un uso mayoritario. En segundo lugar, el pronombre de tercera persona y, por último, el demostrativo este.

\subsection{Deixis espacial: los adverbios de lugar allí, allá, aquí y acá}

Un acercamiento a la sistematización de estos adverbios se debe a Carbonero (1979). Para este estudioso, estos adverbios presentan una correspondencia entre cualquiera de las tres personas, puesto que sirven para situar la acción verbal a partir del punto de referencia: al hablante le corresponderán las formas aquí, acá, al oyente ahí y allí o allá. Agrega, además, que estas formas presentan un rasgo con doble función: locativa, aquí, ahí y allá, y de direccionalidad, como el caso de allá (ejemplo, "voy hacia allá"). Para Eguren (1999), en cambio, estos adverbios se establecen bajo dos subsistemas, uno ternario, aquí, ahí y allá y otro binario, acá y allá. Este autor señala que el primero tiene, por una parte, una correspondencia con los demostrativos este, ese y aquel y, por la otra, constituye relación con el eje deíctico. El segundo expresa sólo lejanía o proximidad en relación con el hablante. ${ }^{3}$ Ahora bien, con base en los postula-

\footnotetext{
3 También debemos recordar que el uso se debe a una distribución dialectal. Las formas con $-i$ se han relacionado con el español peninsular, mientras que la forma con á con el español de América (véase Kany, 1945; Garnes, 2013, entre otros).
} 
dos que realizó Hottenroth (1982) al exponer que las formas en - $i$ indican un lugar más preciso (definidos) contrario a lo que expresan las de -á (indefinidos), mis datos pueden ajustarse a dicha afirmación.

De entre los adverbios a los que he hecho alusión, allí tiene más usos frente a allá, como se puede ver con los ejemplos de (13). En el caso de allí los referentes son precisos: un lugar, una casa y una posada. Mientras que el caso de allá no puntualiza cuál es el lugar al que se refiere:

a. y le dixo donde vas andar conmigo a Quahuchinanco y el dicho Xuchicalcatl fuese con él y aquella noche durmieron Cuxuncupa y de allí se fueron a Quahochinanco (AGN, 1537).

b. están apartados y encerrados en una casa donde no les pasen a mujeres y allí echaban y ofrecían copal a honor de aquel dios (AGN, 1538).

c. y fueron a su llamado a la posada del dicho don Alonso donde posaba el dicho don Carlos y allí les dieron de comer y después de haber comido (AGN, 1539).

d. dixo que al tiempo de su enfermad del dicho don Pablo fue este declarante a lo ver y que después a su fallecimiento fue allá y llevó una manta y en lo demás no sabe (AGN, 1536).

Con respecto al adverbio aquí la correspondencia que se da, como bien afirma Cifuentes, "no viene dada respecto de un elemento espacial o temporal dado contextualmente, sino que está todo dentro del propio significado simbólico de los elementos. 'aquí' es siempre el lugar que ocupa el hablante" (2006: 21). En el ejemplo de (14) aquí es el punto donde se encuentra el escribano y que, por lo tanto, indica un grado de cercanía con su interlocutor.

a. y juró el dicho naguatlato Pedro de Molina [...] en forma de derecho que lo que aquí ha dicho y declarado de lengua de México en lengua española que es la verdad (AGN, 1536). 
El total de uso de los deícticos lo represento en el siguiente cuadro.

\begin{tabular}{|c|c|c|c|c|c|}
\hline Deícticos & Doc. 1536 & Doc. 1537 & Doc. 1538 & Doc. 1539 & Total \\
\hline Allí/aquí & $10 / 4$ casos & $5 / 2$ casos & $3 / 0$ casos & $5 / 1$ casos & $23 / 7=30$ \\
\hline Allá/acá & $6 / 1$ casos & $0 / 4$ casos & $0 / 0$ casos & $2 / 0$ casos & $8 / 5=13$ \\
\hline
\end{tabular}

Cuadro 4. Deícticos allí-aquí /allá-acá

De la información reunida en el cuadro anterior observamos que allí es el adverbio que presenta mayor uso (23) frente a allá con (8) registros. Sigue el adverbio aquí con (7) casos. Mientras que acá sólo tiene (5). Los resultados son pertinentes para comentar que este sistema es binario y que las formas preferidas son las que marcan definitud (-í).

Revisando la sintaxis de los adverbios podemos establecer también que contamos con casos en los que para su construcción es necesaria una preposición, básicamente la estructura se constituye con dos preposiciones de y por; mientras que el adverbio allí emplea de, el adverbio acá empleará la preposición por. En este sentido, de allí es más específico que por acá (el primero indicaría el punto definido y el segundo la aproximación). Veamos los ejemplos de (15).

a. y aquella noche durmieron Cuxuncupa y de allí se fueron a Quahochinanco y el dicho Xuchicalcatl vido en Qualhochinanco como tres mujeres le ofrecieron copal al dicho Andrés (AGN, 1537).

b. Que el dicho Andrés ha hecho daño a lo menos los principales y a que no lo traigan por acá al dicho Andrés (AGN, 1537).

\section{Conclusiones}

Dado el fin de los textos jurídicos que es esencialmente la de informar, describir, argumentar, es menester crear un discurso preciso que evite la confusión y la ambigüedad, por ende, conservar a sus referentes es una de las piezas claves de este tipo de 
discurso. El texto jurídico está cubierto por el uso de anafóricos, desde esta perspectiva estoy de acuerdo con Barra (2008), Garatea (2010) y Arias (2013).

\begin{tabular}{|c|c|c|c|c|}
\hline Estructuras & $\begin{array}{l}\text { Doc. } \\
1536\end{array}$ & $\begin{array}{l}\text { Doc. } \\
1537\end{array}$ & Doc. 1538 & Doc. 1539 \\
\hline \multirow{4}{*}{$\begin{array}{l}\text { art + adv (el dicho) } \\
\text { dem + dicho (este } \\
\text { dicho) } \\
\text { art + adv + dicho lo } \\
\text { susodicho } \\
\text { art + adv + adv } \\
\text { (lo susodicho de arriba) }\end{array}$} & 35 & 56 & 37 & 64 \\
\hline & 12 & 6 & 8 & 16 \\
\hline & 13 & 7 & 10 & 14 \\
\hline & 0 & 1 & 0 & \\
\hline \multirow{3}{*}{$\begin{array}{l}\text { Relativo compuesto } \\
\text { (los cuales) } \\
\text { pronombre personal } \\
\text { (ellos) } \\
\text { demostrativo: } \\
\text { este/aquel } \\
\end{array}$} & 16 & 24 & 12 & 8 \\
\hline & 12 & 6 & 6 & 10 \\
\hline & $31 / 10$ & $10 / 6$ & $12 / 8$ & $8 / 6$ \\
\hline adverbios -í & 14 & 7 & 3 & 6 \\
\hline Total & 143 & 123 & 96 & 132 \\
\hline
\end{tabular}

Cuadro 5. Estructuras con dicho en textos jurídicos

Así pues, los usos del participio que registré en la documentación colonial el más frecuente es artículo + dicho para personas y objetos, y artículo + sobredicho para partes del discurso ya enunciadas. El escribano emplea esta forma como un uso 'enfático' agregando siempre el nombre de la persona a la que refiere, debido a que dentro de su universo discursivo desfilan diferentes nombres y para guiar al lector debe ser muy específico y, por ende, se ve en la necesidad de volver a nombrar a su referente, de lo contrario causaría una confusión y la atención al referente se perdería.

Con base en los datos analizados puedo responder a la primera pregunta que hice al inicio y, señalo que la construcción artículo + dicho que se empleó en el siglo XIV cruzará el océano 
y llegará a formar parte de la nueva realidad textual jurídicaamericana en los manuscritos de los escribientes. Con respecto a la segunda pregunta, se confirma que aparte de la forma del participio de 'decir' dicho los anafóricos más recurrentes serán: el uso del pronombre relativo compuesto, después, los demostrativos y, finalmente, el pronombre de tercera persona.

La justificación que doy para contextualizar el apartado sobre las estructuras con la forma dicho radica en que los pocos estudios sobre este tema han centrado su interés en esta estructura, pero es cierto también que se han dejado de lado los otros usos de anafóricos y deícticos. Por lo que puedo decir que la forma el dicho es el telón de fondo para dar continuidad al estudio de los otros recursos que empleó cada secretario, como se trató de exponer en estas líneas.

Los resultados que muestro en los cuadros 2 y 3 nos permiten corroborar que los anafóricos son pieza clave para la construcción del discurso jurídico porque son, como bien ha señalado Eguren (1999), actualizadores de la información.

Con respecto a los deícticos el uso se centra en los adverbios espaciales allí, allá y aquí y acá. El empleo de allí es el que presenta mayor número de casos, así como también un punto preciso de lugar, contrario a allá y acá. Recordemos que para el secretario la localización se convierte en el hilo conductor para el desarrollo de los hechos, es de suma importancia ubicar el lugar de los acontecimientos.

Asimismo, es importante señalar que cada secretario utiliza anafóricos y deícticos para organizar su discurso y delimitar tanto los hechos como los personajes, y a la vez, dada la versatilidad que poseen estas formas lingüísticas, se convierten en un recurso para precisar o ubicar la información que se quiere proporcionar.

Este trabajo no agota el estudio de los deícticos y anafóricos, deja una puerta abierta para futuras investigaciones. No obstante, a partir de los datos analizados se puede afirmar que las construcciones con dicho, las formas este, cual, pronombres deben ser frecuentes en el discurso jurídico. Así pues, los adverbios aquí/allí, acá/allá hacen referencia a lo extralingüístico 
y serán menos usados. En este sentido, también puedo afirmar que el canon peninsular continúa en los escritos novohispanos.

Por último, es menester señalar que estas estructuras lingüísticas favorecen la claridad del discurso e impiden que haya confusiones en cuanto a los actores y eventos, al tiempo que permite anclar tales usos en el proceso básico de redacción, pues al ser documentos jurídicos estas unidades son indispensables debido a que se encargan de organizar y actualizar la información que se genera en un tiempo y en un espacio determinados.

\section{Bibliografía}

Arias Álvarez, Beatriz (2013), "El español en manos indígenas: una aproximación al origen del español colonial mexicano", Signo y Seña, 23, pp. 9-22.

Asenjo Orive, María Rosa (1973), Los demostrativos, Salamanca, Publicaciones del Colegio de España.

Barra Jover, Mario (2008), “Tradición discursiva, creación y difusión de innovaciones sintácticas. La cohesión de los argumentos nominales a partir del siglo xiII", en Johannes Kabatek (ed.), Sintaxis histórica del español y cambio lingüistico: nuevas perspectivas desde las Tradiciones Discursivas, Madrid, Iberoamericana/Vervuert, pp.127-149.

Barrenechea, Ana María (1984), Estudios de gramática estructural, Buenos Aires, Paidós.

Bizcarrondo, Gema (1995), "El lenguaje jurídico. Razón pragmática y razón filológica”, Estudios de Deusto, 43:1, pp. 1-79.

BüHler, KARL ([1934] 1979), Teoría del lenguaje, Madrid, Alianza.

Carbonero Cano, Pedro (1979), Deixis espacial y temporal en el espacio lingüístico, Sevilla, Publicaciones de la Universidad de Sevilla.

Cifuentes Honrubia, José Luis (1989), Lengua y espacio. Introducción al problema de la deixis en español, Alicante, Universidad de Alicante. 
Cifuentes Honrubia, José Luis (2006), La deixis, Madrid, Liceus/ E-excellence.

Corominas, Joan y Pascual José Antonio (1980), Diccionario crítico etimológico castellano e hispánico, Madrid, Gredos.

Eguren, Luis (1999), "Pronombres y adverbios demostrativos. las relaciones deícticas”, en I. Bosque y V. Demonte (dirs.), Gramática descriptiva de la lengua española, Madrid, Espasa-Calpe, pp. 929-972.

Fillmore, Charles J. (1997), Lectures on deíxis, Stanford, CSLI Publications.

Garatea Grau, Carlos (2004), "Español de América, español de Perú. Sobre normas y tradiciones discursivas", Lexis, XXVIII:1-2, pp. 397-428.

Garatea Grau, Carlos (2010), Tras una lengua de papel. El español de Perú, Lima, Pontificia Universidad Católica del Perú.

Garnes Tarazona, Inmaculada (2013), "Deixis espacial en el español peninsular: el caso de allí y de allá”, Signos Lingüísticos, IX:17, pp. 101-115.

GITHE (Grupo de Investigación Textos para la Historia del Español), CODEA + 2015 (Corpus de documentos españoles anteriores a 1800) [en línea] <http://www.corpuscodea.es> [Consultado en febrero de 2018.].

Hottenroth, Priska Monika (1982), “The system of local deixis in Spanish", en J. Weissenborn y W. Klein (eds.), Here and There: Crosslinguistic studies on deixis and demonstration, Ámsterdam, John Benjamins, pp. 133-153.

Kany, Charles E. (1945), American- Spanish Syntax, Chicago, Chicago University Press.

LAPESA, RAfAel (1961), "Del demostrativo al artículo”, Nueva Revista de Filología Hispánica, XV:1/2, pp. 23-44.

Mendizábal de la Cruz, Nieves (1998), "Formas de expresión del lugar y la dirección en español”, en $\underline{\text { M. Á. Celis }}$ Sánchez y J. R. Heredia (coords.), Lengua y cultura en la enseñanza del español a extranjeros: actas del VII Congreso de ASELE, Albacete, Universidad de Castilla-La Mancha, pp. 309-316. 
Pottier, Bernard (1962), Systematiqué des elements de relation. Étude de morphosyntaxe structurale romane, París, Klincksieck.

Terrado Pablo, Xavier (1990), "Sobre la forma de contenido de los adverbios de lugar. Cuestiones de diacronía”, Sintagma:Revista de Lingüística, 2, pp. 56-66.

Sánchez Lancis, Carlos E. (1990), Estudio de los adverbios de espacio y tiempo en el español medieval, tesis de doctorado, Barcelona, Universidad Autónoma de Barcelona.

Vicente Mateu, Juan Antonio (1994), La deixis. Egocentrismo y subjetividad en el lenguaje, Murcia, Universidad de Murcia.

\section{Manuscritos}

AGN, Inquisición, 61 exp. 4, vol. 38, 1536.

AGN, Inquisición, 61 exp. 7, vol. 38, 1537.

AGN, Inquisición, 61 exp. 8, vol. 22, 1538.

AGN, Inquisición, 61 exp. 10, vol. 2, 1539.

Idanely Mora Peralta es licenciada en Lengua y Literaturas Hispánicas, maestra y doctora en Lingüística, por la Facultad de Filosofía y Letras de la UNAM, los dos últimos grados con mención honorífica. Publicaciones: "Topónimos y antropónimos en documentos coloniales del siglo XVII" en las actas del X Simposio Internacional de Comunicación Social. Centro de Lingüística Aplicada. Ministerio de Ciencia, Tecnología y Medio Ambiente, Santiago de Cuba, Cuba, 2007; "Estudio Gráfico- fonológico de apelativos mayas" en Mosaico de estudios coloniales. (1 Coloquio Internacional Lenguas y Culturas Coloniales, 2008) coord., Beatriz Arias Álvarez et al. México, UNAM, 2013; "Sonetos injuriosos: resultado de la predicación de un sermón del siglo XVII” en De monjas, Crónicas, Burlas y Amores ed. Margarita Peña, México: ADABI, marzo, 2014. Colaboradora en el libro Documentos públicos y privados del siglo XVI. Textos para la historia del español colonial mexicano 1. Directora, Beatriz Arias Álvarez, UNAM-IIFL, 2014. Ela- 
boración del índice de antropónimos del libro Documentos públicos y privados del siglo XVI. Textos para la historia del español colonial mexicano 1, 2014; "Análisis lingüístico de una carta del siglo XvII, contacto maya-español." en el Anuario de Letras (2016). Asimismo, es colaboradora responsable de la edición del corpus electrónico COREECOM (Corpus electrónico del español colonial mexicano) del IIFL-UNAM. Es miembro de la Red Internacional: Corpus Hispánico y Americano en la Red: Textos Antiguos. Es profesora en el nivel superior en la FFyL de la UNAM y en la Escuela Nacional de Antropología e Historia, INAH. Reconocimientos: con la tesis de licenciatura obtuvo la Mención Honorífica en el premio Wigberto Jiménez Moreno en la categoría de Tesis de Licenciatura Topónimos y antropónimos mayas en documentos coloniales del siglo XVII, correspondiente al área de Lingüística entregado por el Instituto Nacional de Antropología e Historia (2009). Como colaboradora del libro Documentos públicos y privados del siglo XVI. Textos para la Historia del español colonial I, se obtuvo el premio RAE en Investigación Filológica 2015. Ha participado como ponente en eventos académicos nacionales e internacionales. Ha cursado más de una veintena de cursos en universidades nacionales y extranjeras. Es investigadora del Centro de Lingüística Hispánica J. M. Lope Blanch, del IIFL. Sus líneas de investigación son: gramática histórica, el español novohispano, las tradiciones discursivas, lenguas en contacto: español- maya/ español- gallego. 